\title{
Transição malograda de um poder emergente? A participação brasileira nas negociações tarifárias da Rodada Tóquio
}

\author{
Thwarted transition of an emerging power? Brazilian \\ participation in the tariff negotiations of the Tokyo Round
}

ROGÉRIO DE SOUZA FARIAS*

Rev. Bras. Polít. Int. 51 (2): 179-196 [2008]

\section{Introdução}

Este artigo perscrutará a participação brasileira nas negociações tarifárias do GATT na rodada Tóquio (1973-1979). Será argumentado que houve uma mudança da posição do Itamaraty sobre os benefícios que o país poderia ter em barganhar interesses concretos nessas negociações. O que justificou tal mudança foi uma percepção distinta do interesse nacional, dinâmica associada ao crescimento da economia brasileira, à experiência com as negociaçôes comerciais da década de 1960 e ao crescente unilateralismo americano. Essa percepção, porém, não era generalizada no aparelho estatal, de forma que outros órgãos governamentais impediram que a nova estratégia do Itamaraty fosse implementada de maneira adequada ${ }^{1}$.

A análise do caso é relevante por quatro motivos. Primeiro, apesar de a literatura considerar a política externa brasileira do período dentro do marco de uma "autonomia pela distância", é visível uma mudança das crenças dos diplomatas sobre os benefícios que o país poderia ter nas negociaçóes comerciais multilaterais do Gatt, inclusive na área tarifária (Fonseca Jr.: 1998, 359-63; Lafer: 2000, 263-5; Ribeiro: 2006). Segundo, mesmo sendo essa transição de crenças condição necessária para uma mudança da posição do país, será argumentado que a participação de outros atores governamentais no processo decisório obstaculizou um ativismo maior no plano multilateral, o que demonstra como a política econômica externa era bem mais complexa do que a simples retórica

\footnotetext{
* Mestre e Doutorando em Relaçôes Internacionais pela Universidade de Brasília - UnB (rofarias@gmail.com). 1 Este artigo é extensivamente baseado na dissertação de mestrado do autor, intitulada O Brasil e o GATT (1973-1993): unidades decisórias e política externa, apresentada ao Programa de Pós-Graduação em Relações Internacionais da Universidade de Brasília em 2007.
} 
diplomática aparenta à primeira vista. Terceiro, o exame do caso demonstrará que, apesar de o país voltar-se, na década de 70 , para um processo de diversificação de exportaçôes, é nítido que, quando este se chocava com as necessidades de proteção ao mercado doméstico, o potencial exportador era sacrificado. Por fim, o caso é também relevante para apresentar a participação brasileira em um dos principais nichos de ação do Gatt: as negociações tarifárias (Hoda: 2001, 5). ${ }^{2}$

A primeira seção examinará o marco geral da mudança de posição brasileira em negociações comerciais internacionais. $\mathrm{O}$ texto prosseguirá com o exame das negociações tarifárias da rodada Tóquio. Por fim, será realizada uma conclusão, que sistematizará as contribuições analíticas do caso para o estudo da política externa brasileira.

\section{Poder emergente e novos interesses}

No período que vai de meados da década de 1950 até 1968, o Brasil teve discurso bastante crítico ao Gatt. ${ }^{3} \mathrm{O}$ país procurava, de forma tenaz, a migração das questōes atinentes ao comércio internacional para a UNCTAD. ${ }^{4}$ Era simples a atuação brasileira no Gatt: ter "as reivindicações (...) mais amplas e ambiciosas possíveis - dado que (...) para pressionar o Gatt, conta[va-se] com a alternativa da [UNCTAD]." Essa posição, no entanto, não perdurou na década de 1970. Com exuberante crescimento econômico, foi-se cristalizando a crença "de que o país podia, efetivamente, transcender suas circunstâncias históricas, melhorar seu posicionamento relativo na estrutura internacional de poder" (Spektor: 2004, 196). Acreditava-se, assim, que a futura ascensão brasileira como grande potência seria um dos aspectos mais significativos da política internacional após a II Guerra Mundial (Schneider: 1976, xiii). Essa nova situação teve impactos relevantes na política econômica externa do país, mormente em sua dimensão multilateral.

Porém, mesmo considerando que o país poderia, no futuro, estar no círculo dos países desenvolvidos, o Brasil continuava ideologicamente comprometido com a reestruturação das relações internacionais e com a redistribuição da riqueza internacional. Essa preocupação modulava a projeção externa do país de forma a

2 Marcelo de Paiva Abreu afirma, por exemplo, que antes de 1960 o principal envolvimento do Brasil no Gatt relacionava-se com a renegociação de tarifas (Abreu: 1993, 142).

3 Informação para o Embaixador Antônio Francisco Azeredo da Silveira. 24 de março de 1966. AAS 1966.03.24. Ver também (Batista: 1991, 3).

4 Era explícito o desejo do Brasil que o Gatt desaparecesse e desse lugar a uma instituição nos moldes da UNCTAD. Nos documentos brasileiros dava-se o nome de "Organização Internacional de Comércio e Desenvolvimento" a essa organização. Assim, a ação brasileira até então era vista como "apenas um primeiro passo num longo caminho que, idealmente, levaria o Gatt a integrar-se completamente no sistema da CNUCD[UNCTAD], e na eventual criação de uma Organização Internacional do Comércio e Desenvolvimento". Divisão de Política Comercial. Informação para o Embaixador Antônio Francisco Azeredo da Silveira. 24.03.1966. AAS 1966.03.24.

5 De Ovídeo Melo para Jaime A. Rodrigues. 22 de agosto de 1963. MRE (CDO/Brasília). 1964.375.05.1 
caracterizá-la como reformista. ${ }^{6}$ No lado econômico, destaca-se o posicionamento brasileiro de derrubar constrangimentos externos às políticas domésticas voltadas para o desenvolvimento - vinculado principalmente a uma mentalidade desenvolvimentista e a um tratamento político de temas econômicos.

Araújo Castro, por exemplo, afirmava que o Brasil não pode [ria] aceitar peias e entraves na livre arrancada para o seu pleno desenvolvimento econômico (Castro: 1972, 22). Assim, o objetivo da ação brasileira no mundo deveria ser (...) remover quaisquer obstáculos que possam oferecer-se contra o seu pleno desenvolvimento econômico, tecnológico e científico (...) (Castro: 1972, 2). Azeredo da Silveira expressava opinião semelhante, ao afirmar que o Brasil deveria almejar "prescindir de outras naçôes líderes naquilo que for essencial à consolidação de seu desenvolvimento"?

Mas a realização desse objetivo, em fóruns multilaterais econômicos, não poderia ser alcançada pela estratégia até então adotada. De acordo com Barthel Rosa, chefe da Divisão de Política Comercial do Itamaraty em 73, o Brasil deveria atuar em tópicos concretos e negociáveis e não por declarações gerais e pouco claras. ${ }^{8}$ Outros diplomatas em Brasília demonstravam-se pessimistas quanto aos possíveis frutos das iniciativas de outros países em desenvolvimento. Considerava-se a Carta de Direitos e Deveres Econômicos dos Estados, por exemplo, uma grande colcha de retalhos que não corresponderia aos interesses do país. ' Paulo Nogueira Batista, diplomata brasileiro em Genebra, também afirmava que a discussão de iniciativas genéricas de reforma ou criação de uma nova ordem econômica internacional era tema abstrato, complexo e polêmico, que, ao seu ver, não ajudava os países em desenvolvimento, principalmente por desviar esforços da etapa de preparação do que viria a ser a Rodada Tóquio do Gatt. Era o momento de a UNCTAD e outros órgãos confrontarem-se com tópicos mais concretos e menos declaratórios, até mesmo para aumentar sua credibilidade junto aos países desenvolvidos. ${ }^{10}$

Os potenciais ganhos da promoção dos interesses brasileiros em certas instâncias multilaterais continuou a incomodar os quadros do Itamaraty. Em outubro de 1973, o diplomata Souto Maior comentava a utilidade cada vez mais discutível para nós de uma organização [UNCTAD] em que o Brasil se [vê] crescentemente forçado a posições defensivas. Para ele, não deveria haver hesitação

\footnotetext{
6 Esse aspecto era visível para observadores externos. Nara. Da embaixada americana em Brasília para o State Department. Possible themes and initiatives for Secretary's visit to Brasil - an overview. Third Part. 25 de março de 1975. Secreto.

7 "Silveira: potência em 20 anos". O Estado de São Paulo. 18 de julho de 1976.

8 Nara. De John Crimmins (Brasília) para o State Department. CECLA meeting: GOB views on trade declaration. 29 de agosto de 1973.

9 Desptel 892. UNCTAD. II Sessão do GT sobre a Carta de Direitos e Deveres Econômicos dos Estados. Instruçōes. 7 de julho de 1973. Rolo 1801. Telegramas expedidos (DELBRASGEN).

10 Tel 1730. XVIII Assembléia Geral. Item 51 da agenda. UNCTAD. Carta dos Direitos e Deveres Econômicos dos Estados. 21 de setembro de 1973. Rolo 1792. Telegramas recebidos (DELBRASGEN).
} 
na crítica severa tanto da organização em si como da política pouco construtiva dos países que a compõem. ${ }^{11}$ As idéias de Souto Maior seriam futuramente compartilhadas por Azeredo da Silveira, que afirmou:

Reconheço que a nossa atuação nos órgãos econômicos da ONU se tornou mais difícil na medida em que evoluímos da formulação de princípios gerais para a elaboração de normas ou recomendaçóes mais específicas, nos quais os interesses dos vários países em desenvolvimento podem, muitas vezes, divergir. ${ }^{12}$

Essa declaração de Silveira é relevante, pois indica uma "especificidade" dos interesses brasileiros no sistema multilateral de comércio, ou seja, demandas concretas em vez da retórica obstrucionista que caracterizou a posição do país durante vários anos. Mas isso não se traduziu de forma automática em apoio às negociações da Rodada Tóquio. Inicialmente, Silveira propôs uma reforma do sistema multilateral semelhante à de vários países em desenvolvimento. Era uma proposta de Acordo Comercial Norte-Sul, a qual deveria proporcionar uma matriz político-jurídica para negociações específicas. ${ }^{13}$ Essa posição foi logo abandonada, tendo o Itamaraty voltado consideráveis esforços para as negociações do Gatt. O raciocínio dos diplomatas era o seguinte: ficar de fora ou ser passivo de nada adiantaria, pois o Brasil mantinha mais de $70 \%$ de seu comércio exterior com os Estados Unidos, a CEE e o Japão, países que participariam das negociações comerciais e que, de acordo com a visão do período, tratariam de impor os resultados aos demais. O Brasil, de acordo com Silveira, deveria participar de forma ativa, porque "se não participássemos, seríamos punidos e somos uma presa suculenta para os países industrializados". ${ }^{14}$

O Chanceler via a não participação brasileira nas negociações do Gatt como prejudicial ao interesse nacional, pois excluiria o país da definição do importante sistema de regras que regularia os fluxos comerciais do país com o exterior. Considerar que o Brasil desejava maior poder e ativismo, no entanto, não significava que havia concordância com os princípios subjacentes ao arranjo multilateral. Muito pelo contrário, buscava-se, de forma tenaz, um sistema de regras que desse liberdade para o país restringir importações e subsidiar exportações, além de regras mais rígidas que impedissem os países

11 Telegrama sem número. Pedido de retransmissão de telegrama. 31 de outubro de 1973. Rolo 1792. Telegramas recebidos (DELBRASGEN).

12 Desptel 1384. Instruções. 4 de novembro de 1977. Rolo 2097. Telegramas expedidos (DELBRASGEN). 13 "Silveira volta e defende proposta". O Estado de São Paulo. 4 de setembro de 1975; "Silveira repetirá proposta de acordo geral na ONU” O Estado de São Paulo. 12 de setembro de 1975. Crimmins, embaixador americano no Brasil, julgava que isso se devia ao fato de os diplomatas brasileiros estarem muito ocupados com as negociaçôes da Rodada Tóquio. Nara. De John Crimmins (Brasília) para o State Department. 30th UNGA - Agenda item 123 (Brazilian trade agreement proposal). 3 de novembro de 1975. Confidencial.

14 "Gatt poderá alterar incentivos". O Estado de São Paulo. 29 de janeiro de 1978; "Silveira critica política dos EUA" Gazeta Mercantil. 20 de setembro de 1978. 
desenvolvidos de adotarem essas mesmas estratégias. ${ }^{15}$ Fica claro, portanto, que, antes, acreditava-se que esses objetivos só poderiam ser alcançados fora do Gatt. Contudo, diante da experiência dentro do bloco dos países em desenvolvimento e o crescente unilateralismo norte-americano, pragmaticamente observava-se que a solução normativa de reforma estava no próprio arranjo.

Assim, a percebida relevância das negociaçóes da rodada Tóquio para os destinos do país era acompanhada pela crença de que a participação do país não poderia ser encetada, tanto no curto quanto no longo prazo, nas regras atuais da organização. Era necessária uma mudança das regras do jogo. Foi daí que nasceu o objetivo do Itamaraty de realizar uma reforma profunda no Gatt, por intermédio do que viria a ser chamado de Framework Group (Maciel: 1977, 141-6; Winham: 1986). ${ }^{16} \mathrm{O}$ Itamaraty, desde o início, estava ciente que o avanço nas negociações de reforma do Gatt só viriam com uma flexibilização da posição do Brasil em outras áreas, inclusive na sua oferta tarifária - havia um linkage entre os dois assuntos. A concepção de que o país deveria fazer concessões na área tarifária, para conseguir alcançar seus objetivos normativos denota significativa mudança de posição em negociações comerciais multilaterais. Não há, por conseguinte, razão para considerar que houve uma concepção de autonomia pela distância no Itamaraty.

Apesar de ter ocorrido sensível transformação das crenças do Palácio dos Arcos, não podemos afirmar que o país se comportou de forma equivalente no plano multilateral. A razão para isso está no fato de o órgão não ter tido o controle do processo de definição da posição no tópico de tarifas da rodada Tóquio. Houve, portanto, conflitos entre o ministério e as áreas econômicas do governo, que não estavam pré-dispostas a ceder na área tarifária em troca de ganhos no desenho processual e normativo do sistema multilateral de comércio. Na próxima seção, esse conflito será examinado.

\section{Negociações tarifárias na Rodada Tóquio}

A instância que funcionaria como "núcleo de formulação, coordenação e execução da política brasileira” para as negociaçōes no âmbito da Rodada Tóquio do Gatt era a Unidade de Negociação (UN). Ela era presidida pelo SecretárioGeral Adjunto para Assuntos Econômicos do Ministério das Relações Exteriores

15 Ver, por exemplo, Special procedures for developing countries. Working paper presented by the Brazilian Delegation. MTN/W/2. 26 October 1973; The generalized system of preferences and the multilateral trade negotiations. Statement by the Brazilian delegation. COM.TD/93. 15 June 1973. O exame da atuação do Brasil nas negociaçōes do Código de Subsídios e Medidas Compensatórias é igualmente relevante no exame dessa dualidade (Farias: 2007, 117-56).

16 A iniciativa nasceu de um discurso de George Maciel: [s] ince the outset of these negotiations [Rodada Tóquio], Brazil has believed that one of its most important aspects (...) was the improvement of the international framework for the conduct of world trade. Statement by the representative of Brazil, H.E. Ambassador George A. Maciel, on 21 february 1977. MTN/FR/W/1. 21 february 1977. 
e integrada por representantes do Ministério da Fazenda, do Ministério da Indústria e Comércio, do Ministério do Planejamento e Coordenação Geral, do Banco do Brasil, do Conselho de Política Aduaneira do Ministério da Fazenda e da CACEX. ${ }^{17}$ Seu posicionamento preliminar na área tarifária era que o país deveria manter uma posição defensiva de expectativa interessada. ${ }^{18} \mathrm{~A}$ razão de tal letargia não está em qualquer crença do Itamaraty, até porque, como foi visto, as crenças dos diplomatas levariam a uma posição ativa do país. A explicação da posição brasileira reside em outro domínio, mais particularmente na atuação de outros órgãos - o que demonstra como o Itamaraty era dependente do trabalho técnico de outros órgãos da administração. Isso é claro quando se lê a instrução do início da rodada Tóquio:

Dada a alta natureza técnica dos assuntos que entrarão em pauta (...), o Brasil ainda não pode estabelecer uma posição sobre os mesmos, sendo necessário, para isso, haver uma definição dos órgãos internos competentes. ${ }^{19}$

No ponto específico da área tarifária, o Itamaraty, em Brasília, sempre alertava a delegação em Genebra para o fato das decisões sobre qual o curso de ação que o Brasil deveria tomar ser definido (...) por órgão colegiado integrado pelas diversas áreas competentes do governo brasileiro, e não pela Chancelaria, daí a dificuldade em encaminhar as respostas das consultas da delegação em Genebra na velocidade adequada. ${ }^{20}$

Seria só em 75, na sétima reunião da Unidade de Negociação, que seriam criados os grupos de trabalhos para formular a posição brasileira nos diversos tópicos da agenda da Rodada. ${ }^{21} \mathrm{O}$ Grupo $\mathrm{G}$-integrado pelo Itamaraty, Ministério da Fazenda, Ministério da Indústria e Comércio, Banco Central, CPA, CACEX, Confederação Nacional da Indústria e Confederação Nacional do Comércio lidaria, inicialmente, com a construção da posição brasileira na área tarifária da Rodada. A primeira reunião foi marcada para fevereiro de 1976, mas só ocorreria em setembro do mesmo ano. ${ }^{22} \mathrm{~A}$ razão da demora parece ter sido o receio nutrido tanto pela CACEX quanto a CPA sobre os riscos de o Brasil ser exigido a prestar contrapartidas tarifárias em um contexto de potenciais problemas no balanço de

17 Criada pelo Decreto 72.161, de 30 de abril de 1973.

18 Desptel No 37. GATT. NCMs. Perspectivas atuais. Em 15 de janeiro de 1974. Rolo 2097. Telegramas expedidos (DELBRASGEN).

19 Desptel No 502. GATT. NCMs. Grupo de Barreiras não-tarifárias. Reunião de 7 de maio. Em 6 de maio dem 1974. Rolo 2097. Telegrmas expedidos (DELBRASGEN).

20 Desptel No 909. Gatt. Lista III. Reunião do Conselho de Representantes do dia 11 de julho. Em 7 de julho de 1975. Rolo 2105. Telegramas expedidos (DELBRASGEN).

21 Desptel 1216. Gatt NCM's. Unidade de Negociação. VII reunião. Resultados. Em 19 de setembro de 1975. Rolo 2105. Telegramas expedidos (DELBRASGEN).

22 Desptel No 84. Gatt. NCM’s. Unidade de Negociação. 2a fase dos trabalhos. VIII reunião. Resultados. Em 23 de janeiro de 1976. Rolo 2112. Telegramas expedidos (DELBRASGEN). 
pagamentos do país. Com efeito, em 75, dois anos após o choque do petróleo, os dois órgãos buscavam de forma tenaz a contração das importaçōes e o avanço da substituição de importações em novos setores da economia. É isso que justifica a posição dos dois órgãos na segunda reunião do grupo, no início de outubro de 76, quando eles consideravam prematuro até trabalhos internos para definição de listas de pedidos e ofertas em acesso a mercados. ${ }^{23}$

Observa-se, dessa maneira, que, desde o início das atividades do grupo de trabalho, conflitos burocráticos apresentavam-se na interação dos órgãos do governo para definir a posição brasileira. O Itamaraty, tentando aumentar a credibilidade dos negociadores em Genebra, insistia para que o CPA e a CACEX começassem um programa de trabalho para definir listas preliminares de pedidos e ofertas. Esses dois órgãos, no entanto, consideravam a iniciativa inadequada, utilizando a desculpa de que não conheciam, naquele momento, as medidas de tratamento diferenciado nestas áreas sobre as quais basear seus pedidos. Assim, para os negociadores em Genebra, não restava alternativa senão rebuscar o discurso na demanda por modalidades de tratamento diferenciado, tentando ganhar tempo para que os trabalhos internos iniciassem, possibilitando a preparação adequada da posição brasileira na área tarifária. ${ }^{24}$

Se, no front doméstico, a letargia paralisava o esforço de formulação da oferta, em Genebra, no segundo semestre de 77, a delegação brasileira começava a enfrentar recorrentes pedidos informais para a apresentação de listas de ofertas e pedidos na área tarifária. Em uma ocasião, um representante americano teria afirmado que as autoridades de seu país estavam concluindo uma lista de exceções para negociações tarifárias com base em indicadores de sensibilidade da economia do país, e que, se o Brasil quisesse ter os seus pedidos de acesso ao mercado americano levados em conta, teria de demonstrar seus interesses e ofertas o mais rápido possível. ${ }^{25}$

Analisando esse curto prazo, o representante brasileiro em Genebra, George Maciel, solicitava ao Itamaraty que listas de pedidos e de ofertas na área tarifária fossem enviadas para entendimentos bilaterais. Afirmava que estratégias dilatórias de criar obstáculos procedimentais às negociações, como as adotadas pelo Brasil, não iriam funcionar. Com efeito, os países desenvolvidos já estavam acordando calendário e fórmulas preliminares de redução de tarifas, que condicionariam as negociações, deixando pouco espaço de manobra para quem desejasse atrasá-las ou participar somente em estágio mais avançado. ${ }^{26} \mathrm{~A}$ visão do diplomata era que

23 Desptel No 1193. Gatt. NCM's. Grupo de Tarifas. Em 11 de outubro de 1976. Rolo 2112. Telegramas expedidos (DELBRASGEN).

24 Desptel No 944. Gatt. NCMs: Unidade de Negociação. Em 19 de agosto de 1977. Rolo 2046. Telegramas expedidos (DESLBRASGEN).

25 Tel No 2562. Gatt. NCMs. Tarifas. 16 de novembro de 1977. Rolo 2033. Telegramas recebidos (DELBRASGEN).

26 Esse calendário preliminar foi formalizado no documento Abreviated description of working hypothesis for tariff reductions. 23 december 1977. MTN/INF/17 
aqueles que desejarem efetivamente participar do processo terão de aceitar tais condiçōes, ou permanecer à margem".

A avaliação por George Maciel demonstrava as dificuldades das negociaçôes para o Brasil, pois os principais parceiros comerciais do país afirmavam que, apesar de não quererem reciprocidade estrita, esperavam alguma contribuição. Maciel estava em situação privilegiada para avaliar como as oportunidades que o país tinha na Rodada Tóquio, principalmente na reforma do Gatt eram delimitadas pelo nível de comprometimento por parte do país em outras áreas, notadamente no tópico tarifário. O diplomata também se preocupava com as possíveis perdas na área de acesso a mercados. Observando como as ofertas dos EUA e CEE eram de interesse específico para as exportações do Brasil, Maciel requisitava resoluta tomada de decisão por parte da Unidade de Negociação. Em um texto de síntese dos problemas enfrentados, ele afirmaria:

(...) não devo esconder minha profunda preocupação com o risco crescente de imobilização e marginalização do Brasil nas negociaçôes nesta fase decisiva, as quais, muitos acham, serão as últimas, de tal alcance, no terreno do comércio internacional neste século. ${ }^{27}$

A resposta da Unidade de Negociação não poderia ter sido pior. Apesar de ter tomado conhecimento da solicitação americana, não chegou a conclusões positivas sobre a conveniência da participação do Brasil nas negociações tarifárias, ficando o assunto pendente, inclusive no que toca à possibilidade de apresentação de pedidos de eliminação de barreiras tarifárias na área agrícola, interesse particular do Ministério da Agricultura. ${ }^{28}$ A Divisão de Política Comercial (DPC), órgão interno do Itamaraty responsável por assuntos do Gatt, vendo ruir as chances de êxito para o país na Rodada, envia memorando para Azeredo da Silveira. No documento, é exposto, de forma fria e direta, os prejuízos que o país sofreria se abdicasse de participar das negociações:

Quanto mais reduzida for a área de participação brasileira nas NCMs [Negociações Comerciais Multilaterais], não só mais reduzidas se tornarão nossas possibilidades de obtenção de ganhos significativos nas negociações, como mais difícil se tornará a mera defesa dos interesses brasileiros nas áreas em que decidamos participar. Um afastamento do Brasil da área de negociação de barreiras ao comércio reduzirá consideravelmente nosso raio de manobra na área normativa, além, evidentemente, de reduzir ou eliminar nossos ganhos eventuais em termos de liberalização comercial para os produtos brasileiros de exportação. ${ }^{29}$

27 Tel No 173. GATT. NCMs. Avaliação do estado atual das negociações. 12 de janeiro de 1978. Rolo 1999. Telegramas recebidos (DELBRASGEN).

28 Tel No 37. GATT. NCMs. Reunião da Unidade de Negociação. Barreiras ao comércio. Lácteos. Carnes. Em 11 de janeiro de 1978. Rolo 2015. Telegramas expedidos (DELBRASGEN).

29 Memorandum da DPC para Azeredo da Silveira. As negociações comerciais multilaterais (NCMs). 5 de outubro de 1977. FGV (CPDOC). AAS 1974.03.15 MRE. Pasta VIII. 
O Itamaraty prosseguia tentando mudar a posição do Ministério da Fazenda. ${ }^{30}$ Sem conseguir sucesso no diálogo com Simonsen, Azeredo optaria por levar a dificuldade ao Presidente da República. A questão seria definida por Geisel no início de 1978, em uma reunião realizada no Palácio do Planalto com os ministros da área econômica. ${ }^{31}$ Silveira submeteu relatório ao Presidente, indicando a percepção do Itamaraty sobre as negociações. De acordo com o trabalho, existia, naquele momento, "o risco crescente de imobilização e marginalização do Brasil nas negociações” em decorrência de o Brasil não ter depositado uma lista de ofertas na área tarifária e nem ter reagido aos pedidos de concessão feitos ao país. O mais importante, contudo, foi a pragmática avaliação de que, para o Brasil conseguir qualquer avanço substantivo nas áreas de interesse da Rodada, o país deveria manifestar (...) disposição de oferecer contribuições às NCMs [negociações comerciais multilaterais]. ${ }^{32}$

Azeredo da Silveira, compartilhando as percepções de George Maciel sobre os riscos de o Brasil ser excluído do processo negociador, relatava ao Presidente que os países desenvolvidos reiteradamente explicitavam a expectativa de receber do Brasil alguma forma de contribuição concreta, ainda que sob a égide do princípio de reciprocidade relativa, em troca do atendimento dos interesses brasileiros. Assim, para Silveira, o país teria de atender pelo menos parte dos desejos dos países desenvolvidos para alcançar qualquer resultado substantivo nos pontos de interesse do país nas negociaçôes - ou, no caso, do Itamaraty. ${ }^{33}$

Na reunião interministerial, em fevereiro de 1978, Geisel acabaria apoiando a posição do Itamaraty, o que levaria a uma mudança sensível dos trabalhos da Unidade de Negociação. ${ }^{34}$ Se, antes, o CPA e a CACEX conseguiam adiar qualquer compromisso em estudar seriamente as ofertas e pedidos da área tarifária na rodada, duas semanas após a decisão presidencial acordava-se na Unidade de Negociação a criação de um grupo de trabalho para, em regime de urgência, elaborar uma lista de pedidos brasileiros na área tarifária e formular uma reação aos pedidos feitos até então ao país. ${ }^{35}$ Este grupo - constituído pelo Itamaraty, Ministério da Fazenda, Ministério da Indústria e Comércio, Ministério da Agricultura, CACEX, CPA e CNI - elaborou a lista de pedidos tarifários no

30 Aviso No 375 do Ministério da Fazenda para Itamaraty. 12 de outubro de 1977. FGV (CPDOC). AAS 1974.03.15 MRE. Pasta VIII; Carta de Azeredo da Silveira para Mário Henrique Simonsen. Novembro[?] de 1977. FGV (CPDOC). ASS/Cor. Pasta VIII.

31 Tel No 155. Gatt. NCMs. Participação do Brasil. Reunião com o Senhor Presidente da República. Em 3 de fevereiro de 1978. Rolo 2015. Telegramas expedidos (DELBRASGEN).

32 Desptel No 156. Gatt. NCMs. Participação do Brasil. Informação submetida ao Senhor Presidente da República. Em 3 de fevereiro de 1978. Rolo 2015. Telegramas expedidos (DELBRASGEN).

33 Desptel No 156. Gatt. NCMs. Participação do Brasil. Informação submetida ao Senhor Presidente da República. Em 3 de fevereiro de 1978. Rolo 2015. Telegramas expedidos (DELBRASGEN).

$34 \mathrm{O}$ interessante é observar que elas eram na maioria demandas. "Geisel aprova lista para negociaçōes". Gazeta Mercantil. 3 de fevereiro de 1978.

35 Desptel No 214. Gatt. NCMs. Reunião da Unidade de Negociação. Tarifas. Em 16 de fevereiro de 1978. Rolo 2015. Telegramas expedidos (DELBRASGEN). 
início de março. ${ }^{36}$ É importante salientar que essa lista inicial de oferta foi elaborada pelo Ministério da Indústria e Comércio e não correspondia aos pedidos encaminhados pelos participantes das negociações da odada Tóquio. ${ }^{37}$ Além de não corresponder aos pedidos feitos ao país, podendo ser considerado mais um exercício dilatório, a posição brasileira, em essência, não parece ter mudado tanto. O mais interessante é notar que, mesmo com o aval e o apoio presidencial, o Itamaraty não conseguiu a participação adequada dos órgãos econômicos no processo decisório.

Em abril, vários técnicos da área econômica, além de um representante da CNI, viajaram para Genebra, no primeiro enfrentamento direto com os americanos na área tarifária nessa fase de negociações. Esse grupo definiu no texto critérios técnicos para participação do Brasil nas negociações na área tarifária a posição preliminar do país no tópico. ${ }^{38}$ Nesse texto, explicita-se a tese de necessidade de proteção da produção interna para a manutenção do grau desejável de desenvolvimento econômico, implicando uma posição em que ofertas, mesmo sob o princípio da reciprocidade relativa, seriam muito difíceis de serem apresentadas.

Essa posição relutante de engajamento levou o país a elaborar uma lista de pedidos reconhecidamente inegociável, além de não ter dado uma resposta aos pedidos americanos. ${ }^{39}$ Isso é visto de forma mais clara na afirmação de um técnico de que o Brasil só daria concessões se fossemos atendidos integralmente, em nossas reivindicações, quanto à eliminação de barreiras (...) impostas à penetração dos produtos agrícolas brasileiros. ${ }^{40} \mathrm{O}$ jornal $O$ Estado de São Paulo também comentava, no mesmo sentido, que o Brasil se recusava a participar das negociações tarifárias, porque alguns setores governamentais defendiam uma suposta soberania de política comercial. O veículo, citando fonte em Genebra, asseverava que os países desenvolvidos continuavam afirmando ao Brasil que um avanço nas áreas de interesse do país só viria após receberem alguma forma de contribuição concreta, ainda que sob o princípio de reciprocidade relativa. ${ }^{41}$ Com efeito, em uma reunião com o Embaixador Macdonald, representante dos EUA em Genebra, George Maciel foi informado de que a atitude do Brasil em não aceitar uma discussão sobre as eventuais contribuições à rodada Tóquio

36 Desptel No 293. Gatt. NCMs. Pedidos do Brasil. Tarifas. Barreiras não-tarifárias. Em 2 de março de 1978. Rolo 2015. Telegramas expedidos (DELBRASGEN).

37 Desptel No 361. Gatt. Lista III. Reunião do grupo de trabalho interministerial. 14 de março de 1978. Rolo 2015. Telegramas expedidos (DELBRASGEN).

38 Tel No 992. Gatt. NCM's. Negociações com os EUA. 18 de abril de 1978. Rolo 1999. Telegramas recebidos (DELBRASGEN),

39 Tel No 992. Gatt. NCM's. Negociações com os EUA. 18 de abril de 1978. Rolo 1999. Telegramas recebidos (DELBRASGEN).

40 "Barreira tarifária leva Brasil ao Gatt". Correio Braziliense. 9 de abril de 1978. Ver também: "Antes do Gatt, retaliações na América Latina". O Estado de São Paulo. 9 de abril de 1978.

41 "Antes do Gatt, retaliaçôes na América Latina". O Estado de São Paulo. 9 de abril de 1978. 
antes de conhecidos os benefícios que lhe adviriam ao término da mesma era sinal grave de relutância. De acordo com o diplomata americano, a falta de engajamento brasileiro causaria a retirada das ofertas de interesse do país da mesa de negociação. ${ }^{42}$

Até aqui, portanto, apesar de a decisão pela participação nas negociações tarifárias ser explicada principalmente pelo desejo de o Itamaraty aumentar o respaldo político em outras áreas da rodada ${ }^{43}$, é visível que os órgãos econômicos do governo não estavam entusiasmados com os potenciais ganhos do país. Isso fica mais aparente no momento em que o Ministério da Fazenda começou a coordenar mais ativamente o Grupo de Tarifas da Unidade de Negociação. ${ }^{44}$ É nesse momento que, em uma reportagem na imprensa, relatava-se as sérias restrições de alguns setores que participa[vam] no Governo da elaboração da estratégia do Brasil no Gatt. De acordo com a mesma reportagem, esses setores acreditavam que o Brasil precisava de uma política tarifária flexível para poder instrumentar uma política de substituição de importações. Por isso, a estrutura tarifária não poderia ser consolidada, segundo eles, em função da impossibilidade de se prever em que áreas haverão interesses de se realizar substituições de importações nas próximas décadas. ${ }^{45}$

Prosseguindo o trabalho de definição das ofertas e pedidos brasileiros, o Grupo de Tarifas realizou um exercício de revisão da oferta tarifária do país que, por intermédio do Itamaraty, foi enviado à Delbragen e apresentado aos principais parceiros comerciais. Ao apresentar a oferta em Genebra, George Maciel escutava de negociadores americanos as mesmas críticas sobre a inflexibilidade da posição brasileira, demonstrando que a lista de pedidos pouco realista e a falta de oferta adequada ocasionariam um processo de retirada de ofertas tarifárias americanas, começando pelos produtos em que o Brasil era primeiro fornecedor dos EUA. ${ }^{46}$ A reclamação foi repetida na carta do embaixador americano, Alan Wolff, ao Chefe do Departamento Econômico do Itamaraty, na qual explicita sua decepção com o Brasil nas negociações tarifárias. De acordo com a carta, os negociadores americanos em Genebra tinham feito o máximo para oferecer uma oferta interessante ao Brasil, mas o país se recusava a oferecer compensações dignas, mesmo com reciprocidade relativa. Alan Wolff afirmaria, ainda, que a oferta americana não poderia ser sustentada, muito menos melhorada, se o Brasil não atualizasse a sua. $\mathrm{O}$ embaixador, contudo, se prontificou em fazer

42 Tel No 974. Gatt NCMs. Negociaçōes com os Estados Unidos. 14 de abril de 1978. Rolo 1999. Telegramas recebidos (DELBRASGEN).

43 Desptel No 641. Gatt. NCMs. Reforma do Gatt. 19 de maio de 1978. Rolo 2015. Telegramas expedidos (DELBRASGEN).

44 Desptel No 623. Subgrupo consultivo de comércio Brasil-EUA. 6a sessão. Tarifas. Contribuição do Brasil. Em 15 de maio de 1978. Rolo 2015. Telegramas expedidos (DELBRASGEN).

45 "Brasil vai discutir nos EUA a sua participação no Gatt". Jornal do Brasil. 2 de junho de 1978.

46 Tel No 2804. Gatt. NCMs. Tarifas Estados Unidos. 9 de novembro de 1978. Rolo 2000. Telegramas recebidos (DELBRASGEN). 
um esforço para melhorar a oferta de seu país, atendendo aos pleitos brasileiros, condicionando isso a um esforço brasileiro no mesmo sentido. Terminou a carta afirmando que era melhor uma abordagem positiva nas negociaçôes, com uma renovada oferta de ambos os lados, do que a retirada das propostas, inevitáveis caso não existisse uma oferta melhorada por parte do Brasil. ${ }^{47}$

Novamente, portanto, o Brasil perdeu uma chance de conseguir acesso importante ao mercado americano nos produtos de seu interesse. A resposta brasileira à proposta americana veio em uma carta na qual se afirmava que se os americanos não atendessem aos pedidos brasileiros, o país buscaria um exercício de retiradas recíprocas de ofertas e buscar[ia] um entendimento a um nível global inferior. ${ }^{48}$

Os americanos tentariam mais uma vez, agora com uma carta de Robert Strauss (USTR americano) para Azeredo da Silveira, na qual o americano afirma que não concebia uma forma na qual o Brasil conseguisse sucesso em assegurar acesso a mercado aos seus produtos sem dar também alguma oferta aos americanos. Strauss reafirmaria o alerta de Wolff, dizendo que a posição brasileira iria levar indubitavelmente à redução da oferta americana, prejudicando as pretensões brasileiras. A carta terminava com o pedido para que o país repensasse sua negligente posição. ${ }^{49}$

Azeredo da Silveira levaria as preocupaçōes de Maciel e as demandas americanas para Simonsen, mas não teria sucesso. ${ }^{50}$ Engessado pelas definições rígidas da área econômica, Silveira afirmou, em resposta, que a oferta brasileira era final, dentro dos critérios técnicos autorizados para a participação do Brasil na área tarifária das NCMs, transferindo a culpa para os Estados Unidos, por não ter oferecido melhorias na oferta ao Brasil. ${ }^{51}$ Também asseverou que a justificativa da protelação e a dificuldade em mudar a posição brasileira devia-se às responsabilidades do Ministério da Fazenda e aos trabalhos que envolviam a participação de vários órgãos do governo brasileiro. Por fim, indicou que era a avaliação desses outros órgãos sobre uma nova oferta americana, já que a primeira foi considerada inadequada e não atendeu aos interesses prioritários brasileiros, que iria definir a posição do país nas negociações. ${ }^{52}$

47 Desptel No 1516. NCMs. Carta do Embaixador Wolff. Em 21 de novembro de 1978. Rolo 2015. Telegramas expedidos (DELBRASGEN).

48 Desptel No 1545. Gatt NCMs. Negociações com os EUA. Carta do STR adjunto. Resposta brasileira. Em 27 de novembro de 1978. Rolo 2015. Telegramas expedidos (DELBRASGEN).

49 Desptel No 1554. Gatt. NCMs. Carta do STR. Em 30 de novembro de 1978. Rolo 2015. Telegramas expedidos (DELBRASGEN).

50 Desptel No 1576. Gatt. NCMs. Negociaçōes Brasil-EUA. Em 5 de dezembro de 1978. Rolo 2015. Telegramas expedidos (DELBRASGEN).

51 Desptel No 1603. Gatt. NCMs. Negociaçōes tarifárias. EUA. Em 14 de dezembro de 1978. Rolo 2015. Telegramas expedidos (DELBRASGEN).

52 Desptel No 2. Gatt. NCMs. Negociações Brasil-EUA. Carta do Ministro das Relações Exteriores ao STR. Em 2 de janeiro de 1979. Rolo 561. Telegramas expedidos (DELBRASGEN). 
Essa avaliação veio no início de 79, em uma reunião do Grupo de Tarifas da Unidade de Negociação para definir as instruções brasileiras na área tarifária. Apesar de considerar a hipótese de uma melhora na oferta brasileira, a primeira diretriz definida pelo grupo técnico era reduzir a oferta global brasileira na mesa. ${ }^{53}$ $\mathrm{Na}$ reunião subseqüente, esse objetivo foi ratificado - apesar de sete produtos, que não foram pedidos pelos EUA, terem sua oferta melhorada ${ }^{54}$ Assim, a única alternativa que sobrou nas negociações em Genebra foi construir um pacto mínimo, no qual o Brasil conseguiria a concessão de cinco produtos agrícolas americanos, em troca de concessões em quatro. No setor industrial, em troca do atendimento a pedidos nessa área, o Brasil ofertou oito produtos.

Aqui é interessante analisar como esse caso ilumina o que a literatura recentemente tem argumentado sobre a evolução de um marco desenvolvimentista da política econômica externa do país, fundado no modelo de substituição de importação, para uma modalidade complementar de substituição de exportações (Silva: 2004; Silva: 2005). O caso examinado ilumina a falta de consenso na operacionalização dessa estratégia - dentro da máquina estatal, os órgãos degladiavam-se em torno dos objetivos conflitantes. Dessa maneira, o Itamaraty acreditava nas vantagens de participação na rodada Tóquio, principalmente por identificar que os países desenvolvidos estavam mais abertos às demandas de acesso a mercados por parte dos países em desenvolvimento. Essa posição, contudo, não era compartilhada por outros setores do governo, que ofereciam resistência à participação do país em várias áreas. ${ }^{55}$

O Itamaraty não se acomodou quando se viu frente ao obstáculo da resistência aos seus interesses dentro do próprio governo. Reiteradamente, tomou iniciativas para que o país tivesse uma posição mais ativa no plano multilateral. Essas ações, no entanto, falharam, fazendo com que o Brasil perdesse boas oportunidades de acesso a mercado pela vitória da preferência da proteção do seu mercado doméstico - preferência, aliás, que não era do Itamaraty. Os americanos, por exemplo, desde o início das negociações tarifárias, sempre indicavam que existia possibilidade concreta de flexibilização da posição do país, caso países em desenvolvimento, como o Brasil, se dispusessem a considerar um aumento de concessōes consolidas no Gatt. ${ }^{56} \mathrm{O}$ Brasil acabou preferindo um nível mais baixo de barganha, tendo os próprios diplomatas reconhecido que o país fez poucas concessōes nas negociações. ${ }^{57}$ No duelo entre substituição de importações e

53 Desptel 24. Gatt. NCMs. Negociações tarifárias. Em 11 de janeiro de 1979. Rolo 561. Telegramas expedidos (DELBRASGEN).

54 Desptel 119. Gatt. NCMs. Negociações tarifárias. Em 2 de fevereiro de 1979. Rolo 561. Telegramas expedidos (DELBRASGEN).

55 Tel No 41. Gatt. NCMs. Reforma do GATT. Em 12 de janeiro de 1978. Rolo 2015. Telegramas expedidos (DELBRASGEN).

56 Tel No 178. Gatt. NCMs. Reforma do Acordo Geral. Em 26 de janeiro de 1978. Rolo 1999. Telegramas recebidos (DELBRASGEN).

57 "Acordo do Gatt causa frustração no Itamaraty". O Globo. 13 de abril de 1979. 
substituição de exportações, portanto, a primeira estratégia vencera. O fechamento do mercado doméstico era demasiado relevante para ser barganhado por potenciais aberturas às exportações brasileiras.

\section{Conclusão}

O trabalho examinou a atuação brasileira nas negociações tarifárias da Rodada Tóquio. A política tarifária, no plano doméstico, foi formulada e implementada, no período estudado, pelo CPA e pela CACEX. Essas instituiçóes tinham três poderes que influenciavam a formulação da posição brasileira no Gatt. O primeiro era o poder de formular políticas domésticas que impactavam nas negociações ou nas obrigações do país na referida instituição. Assim, as restrições implementadas em 1975, para tentar dar maior equilíbrio ao balanço de pagamentos, resultaram em mudanças das políticas domésticas, diminuindo as pré-disposições dos órgãos que lidavam com a política comercial para apoiar consolidações tarifárias no âmbito multilateral.

O segundo poder que os órgãos domésticos detinham era o de internalizar ou não o resultado das negociaçōes. Esse poder fez com que a consulta às instâncias formuladoras da política comercial fosse um pré-requisito fundamental para a atuação do Itamaraty; afinal, era pelo cálculo da aceitabilidade dos compromissos internacionais para o ordenamento doméstico que se criava o espaço de possibilidades da cooperação externa. ${ }^{58}$ Essa consulta muitas vezes significava a própria participação dos órgãos formuladores da política comercial no exercício de diplomacia comercial, como foi o caso das viagens de técnicos da área econômica do governo a Genebra.

Por fim, uma outra forma relevante na qual os órgãos domésticos constrangeram o Itamaraty foi a maneira pela qual se processou a definição das instruçōes para os negociadores brasileiros em Genebra. Em situações que afetem importantes políticas domésticas, geralmente há a constituição de uma unidade decisória inter-burocrática para articular a posição externa do país. O Itamaraty, na maior parte do tempo, foi o responsável pela importante função de coordenação interna do processo de formulação da posição brasileira. ${ }^{59}$ Essa atividade habilitou-o a criar estratégias para tentar mobilizar os órgãos domésticos. Desejava, sobretudo, fazer com que suas preferências prevalecessem no processo decisório. No entanto, muitas vezes isso não foi possível - nesses casos, são as preferências e a atuação de outros órgãos do governo que explicam posição externa do Brasil.

Ao contrário do que aparenta à primeira vista, os interesses desses órgãos na posição que o Brasil defenderia no Gatt não são derivados de ciúmes ou

58 Esse é o conceito de win-set, apresentado por Putnam (Putnam: 1993, 438-54).

59 A importância da coordenação no processo decisório em negociações comerciais multilaterais pode ser vista em (Destler: 1980; Lee: 1991). 
contingências subjetivas. Eles tinham diretrizes próprias sobre o nível de proteção tarifária adequado à economia brasileira. Para essas burocracias, uma muralha tarifária era essencial para o desenvolvimento brasileiro e deveria ser preservada de qualquer forma. O mais importante, no entanto, era a percepção de que problemas econômicos - principalmente de balanço de pagamentos - impediam que certas tarifas fossem consolidadas a níveis mais baixos no Gatt, mesmo que isso trouxesse benefícios como uma reforma normativa do sistema multilateral de comércio e um acesso melhor ao mercado americano para os produtos de interesse do Brasil.

Do ponto de vista analítico, fica nítido que o interesse nacional não seria algo pré-determinado ou discernível de condiçôes gerais do posicionamento relativo de um Estado no sistema internacional. A forma pela qual o contexto internacional, os recursos de poder do país e os constrangimentos são mentalmente representados pelos atores governamentais têm grande impacto nas definições estatais (Voss: 1998). O importante, assim, é compreender que nem todos decisores fazem a mesma representação dessas variáveis. A natureza fragmentada da representação de problemas no aparelho de Estado faz com que a análise de processo decisório seja essencial na determinação de quais intenções e idiossincrasias são relevantes na explicação das ações governamentais.

Um aspecto intrigante no caso apresentado é como, no período examinado, o sistema de crenças e percepções do Itamaraty sobre a capacidade e os potenciais ganhos do país em realizar ofertas tarifárias são distintos tanto do período anterior como do período posterior. Com efeito, a posição de obstrução e tenaz aversão do Itamaraty para negociar cortes tarifárias no início da rodada Uruguai contrasta de maneira explícita com a posição brasileira na rodada Tóquio. ${ }^{60}$ A explicação para essa diferença talvez esteja na forma pela qual um poder ascendente entendido como um Estado cujo poder material é limitado no presente, mas que o crescimento econômico promete fazê-lo um dos mais poderosos no sistema internacional (Kennedy: 2007, 1) - sofre constrangimentos e reveses na sua trajetória de longo prazo no sistema internacional, diminuindo os ímpetos para ajustes na política externa. A crise econômica dos anos 80 , assim, poderia explicar a diminuição da confiança do Itamaraty em avançar uma agenda de ofertas na área tarifária, para auferir ganhos em demandas específicas do país. Respostas mais acendradas a essa questão, no entanto, só poderão ser conseguidas com mais pesquisa.

Recebido em 15 de dezembro de 2007 Aprovado em 15 de abril de 2008

60 Um exame preliminar da evolução brasileira na área tarifária do Gatt, desde 1947, pode ser visto em (Farias: 2006). 


\section{Referências bibliográficas}

\section{Fontes primárias:}

CPDOC (FGV). Arquivo Antônio Azeredo da Silveira (AAS).

GATT. Séries: SR.29, L/, MTN/, C/N/

Jornais: Correio Braziliense, Gazeta Mercantil, Jornal do Brasil, O Globo, O Estado de São Paulo.

National Archives (NARA). Archival Database. Central Foreign Policy Files.

Ministério das Relações Exteriores (MRE CDO/Brasília). Despachos telegráficos e telegramas (Genebra). Microfilmes. 1973-1978.

Ministério das Relações Exteriores (MRE CDO/Brasília). Maço 1964.375.05.1 (XCOI-GATT).

\section{Fontes secundárias:}

Abreu, MARCElo de PAIVA. Trade policies and bargaining in a heavily indebted economy: Brazil. In: Tussie, Diana e Glover, David. The developing countries in world trade: policies and bargaining strategies. Boulder: Lynne Rienner Publishers, 1993. p. 137-54.

Batista, Paulo Nogueira. Perspectivas da Rodada Uruguai. Seminário Política Internacional \& Comparada. São Paulo. Junho - 1991, 1991.

Castro, Araújo. O congelamento do poder mundial. Revista Brasileira de Estudos Políticos, v. 33, n. 1, p.7-30. 1972.

DESTLER, I. M. Making foreign economic policy. Washington D.C.: The Brookings Institution, 1980.

FARIAS, Rogério de SouZA. Do Palácio dos Arcos para a Esplanada: o processo decisório da participação brasileira no GATT. 30 Encontro Anual da ANPOCS (GT13 - Ordem hegemônica, multilateralismo e política externa; Sessão 2 - O Multilateralismo Comercial e Agrícola Contemporâneo). Caxambu, MG 2006.

FARIAS, ROGÉRIO DE SOUZA. O Brasil e o GATT (1973-1993): unidades decisórias e política externa_(Dissertação de Mestrado). Brasília: Universidade de Brasília, 2007

FOnseCa JR., GELSON. A legitimidade e outras questões internacionais. São Paulo: Paz e Terra, 1998.

HODA, ANWARUL. Tariff Negotiations and Renegotiations under the GATT and the WTO Procedures and Practices. Geneva and New York: WTO and Cambridge University Press, 2001.

HOPKINS, RAYMOND F. The international role of "domestic" bureaucracy. International Organization, v. 30, n. 3, p.405-32. 1976.

Kennedy, Andrew Bingham. Dreams undeferred: Mao, Nehru, and the strategic choices of rising powers (Ph.D.). Cambridge [Massachusettes]: Harvard University, 2007

LAFER, CELSO. Brasil: dilemas e desafios da política externa. Estudos Avançados, v. 14, n. 38, p.260-7. 2000. 
LEE, CHIN-JUNG. The coordination of US trade policy-making: the role of United States Trade Representative (USTR) (Ph.D). Baltimore: The John Hopkins University, 1991

MACIEL, GEORGE ALVARES. The international framework for world trade: Brazilian proposals for GATT reform (Lectures in Commercial Diplomacy No. 3). London: Trade Policy Research Centre, 1977.

Putnam, RoberT D. Diplomacy and domestic politics: the logic of two-level games. In: Evans, Peter B., Jacobson, Harold K., et al. Double-edge diplomacy: international bargaining and domestic politics. Berkeley: University of California Press, 1993. p. 431-68.

Ribeiro, Cláudio Oliveira. Autonomia e universalismo como condicionantes da política externa brasileira. Revista de Informação Legislativa, v. 43, n. 171, p.133-54. 2006.

SCHNEIDER, RONALD M. Brazil: foreign policy of a future world power. Boulder: Westview Press, 1976.

SIlva, HeloÍSA CONCEIÇÃO MACHADO DA. Da substituição de importações à substituição de exportaçôes: a politica de comércio exterior brasileira de 1945 a 1979. Porto Alegre: Editora da UFRS, 2004.

Silva, Heloísa CONCEIÇÃO MACHADO DA. Da deterioração dos termos de intercâmbio à consolidação do modelo substitutivo de exportações: a política de comércio exterior brasileira de 1954 aos nossos dias. In: O crescimento das relaçôes internacionais no Brasil. Brasília: Instituto Brasileiro de Relações Internacionais, 2005. p. 271-302.

SPEKTOR, Matias. Origens e direção do Pragmatismo Ecumênico e Responsável (1974-1979). Rev. bras. polít. int. , Brasília, v. 47, n. 2, 2004. Disponível em: <http://www.scielo.br/ scielo.php?script $=$ sci_arttext $\&$ pid $=$ S0034-73292004000200007\&lng $=\& \mathrm{nrm}=\mathrm{iso}>$. Acesso em: 02 2008. doi: 10.1590/S0034-73292004000200007.

VOSS, JAMES F. On the representation of problems: an information-processing approach to foreign policy decision making. In: Voss, James F. e Sylvan, Donald A. Problem representation in foreign policy decision making. Cambridge [U.K.]: Cambridge University Press, 1998. p. 8-26.

WInHAM, GILBERT. International Trade and the Tokyo Round Negotiation. Princeton: Princeton University Press, 1986.

\section{Resumo}

O propósito do artigo é analisar a participação brasileira nas negociações tarifárias do Gatt na Rodada Tóquio (1973-1979). Argumentar-se-á que houve uma mudança das crenças dos diplomatas sobre os benefícios que o país poderia ter nas negociações comerciais multilaterais. Contudo, esse movimento não foi generalizado no aparelho estatal, de forma que outros órgãos governamentais impediram a implementação da nova estratégia do Itamaraty de forma adequada.

\section{Abstract}

The purpose of the article is scrutinize the Brazilian participation in the Gatt tariff negotiations of the Tokyo Round (1973-1979). It will be argued that there was a transition in the diplomat's beliefs about the potential benefits that Brazil could obtain in the 
multilateral trade negotiations. Nonetheless, this movement was not generalized within the state apparatus. Therefore, other governmental institutions precluded the implementation of Itamaraty's new strategy.

Palavras-chave: Rodada Tóquio, política externa brasileira, processo decisório e negociações tarifárias.

Key words: Tokyo Round, Brazilian foreign policy, decision-making and tariff negotiations. 